\title{
Similarities in Pronunciation and Meaning of Local Languages and Arabic: Study Contrastive Linguistics of Sundanese Language and Impact on Learning Arabic
}

\section{Alsuna: Journal of Arabic and English Language}

\section{Rizal Firdaus}

Sekolah Tinggi Ilmu Bahasa Arab Ar Raayah Sukabumi

Q rizalfirdaus9@gmail.com

\section{Ana Choerunisa}

Sekolah Tinggi Ilmu Bahasa Arab Ar Raayah Sukabumi

anachoirunnisa71197@gmail.com

\section{Amardin}

Sekolah Tinggi Ilmu Bahasa Arab Ar Raayah Sukabumi

Q amarkamal30@gmail.com

Keywords:

Sundanese Language Dictionary

Sundanese Absorption Words

Arabic Teaching

Article Information:

Submitted: 05 August, 2020

Accepted: 13 November, 2020

Approved: 25 November, 2020

\section{Abstract}

Purpose - This study aimed to reveal the Sunda language words originally from the Arabic in the Sundanese language dictionary of Raden Satdjadibrata. It because the entry and spread of the Arabic language in Indonesia were in line with the entry and spread of Islam in this country. And the entry of Islam carried some words that were not found by the Indonesians before, and it greatly affected their language. Especially, among the Sundanese who use Sunda's language and most of them are Muslim.

Design/methodology/approach - This study was carried out on the qualitative methods based on the theory of Miles and Huberman, with data reduction, data display, and conclusion drawing/verification.

Findings - This study found 92 Sundanese absorption words in the letter $M$ which came from Arabic, and from these words we can group them into four groups. The first, and it is number 58 Sundanese words that their meaning wasn't changed from the Arabic meaning. The second, and its number 8 the words that extended in their meaning. The third, and its number 13 the words that got narrow in their meaning. And the fourth, and its number 13 are the words that changed completely their meaning.

Originality/value - from a number of vocabularies found, can be used to facilitate learning Arabic for Sundanese people. so that it can help understand effectively and efficiently.

Paper type - Concept Paper

المقدمة

كثيرا من الطلاب الإندونيسيين يفضلون تعلم اللغة الإنجلزية على اللغة العربية، ويعتقدون بأنها

لغة عالمية وههمة تعلمها لارتقاء مستواهم الإنساني، ولا يبدلون جهدهم في تعلم اللغة العربية بعلة أنها ليست لغة عالمية . وظن أغلب الإندونيسون أن اللغة العربية لغة عسيرة لما فيها من المشكلات أمام أعينهم عند تعلم هذه اللغة (Al-Adawiyyah 2010). وخاصة عند الشعوب السندويين الذين يستخدمون اللغة السندوية التي تعتبر من أكثر اللغـة المنطقية استخداما في الترتيب الثاني في هذا البلد بعد اللغة الجاوية 
(As-Sa'diyyah 2018) ، فأغلههم يشعرون بصعوبة نطق بعض الأحرف الهجائية، صفة ومخرجا. لعدم وجود بعض الأحرف العربية في لغتهم كحرف " ف "(fha) و"ز ز (zha) . لهذا يجب علينا أن نعلمههم بأن اللغة العربية من اللغات المهمة على مستوى العالم، وإن تعليم تلك

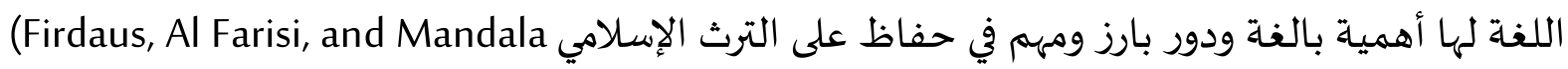

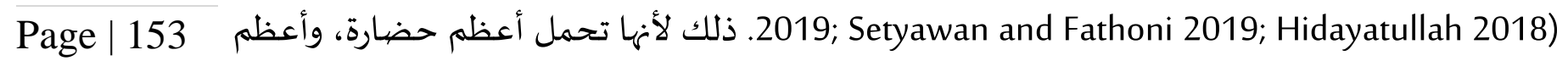
رسالة، فضلا من أهها لغة القرآن الكريم، ولغة الاتصال والتواصل، لأهداف التعلم والتعليم، والعمل، وتبادل الثقافات (Alma'tuq 1996). واللغة العربية هي اللغة التي قدر لها بفضل الله عز وجل أن تستمر



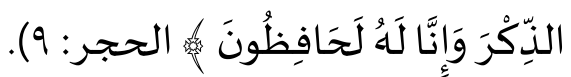
وترتفع الآن النداءات الجادة للاهتمام بنشر اللغة العربية في بلاد العالم بغير الناطقين بها. وتصف

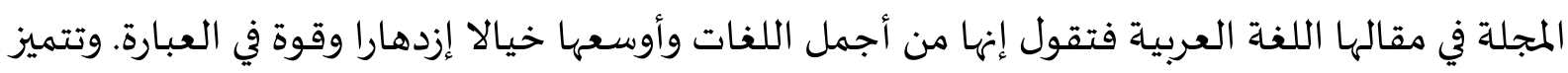
هذه اللغة بكونها لغة الدين بالإضافة إلى كونها اللغة الأم ودستور المسلمين ومنظم حياتههم في الدنيا

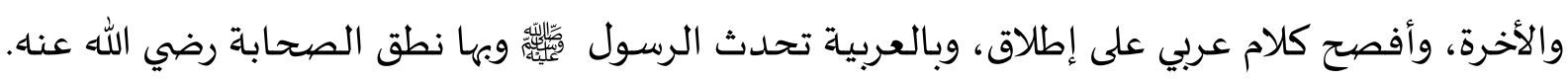

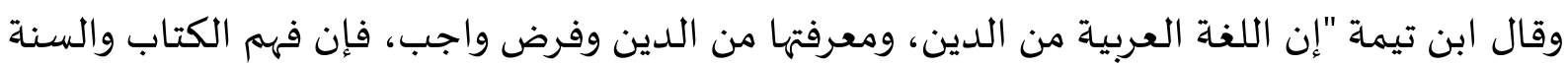
فرض، ولا يفهم إلا باللغة العربية، وما لا يتم الواجب إلا باه فهو واجب" (Al-Fauzan 2011) . ومعرفة هذه مئه

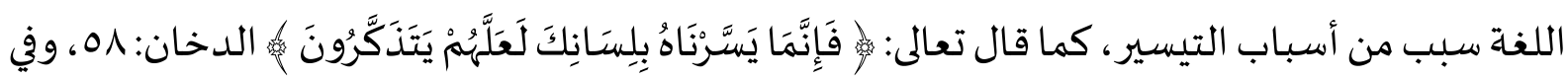

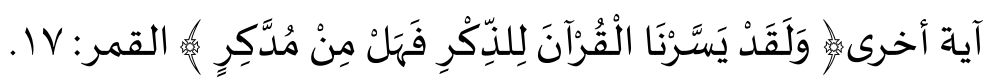
ومن هذا نعرف أن اللغة العربية هي اللغة العالم بل هي أجمل اللغات التي تدوم وتستمر، واعتقاد السندويين بصعوبة تعليم تلك اللغة هو الاعتقاد الخاطئ. ولو كانوا وجدوا الصعوبة في بداية تعلمها، ولكن فئن مع البحث، والمحاولة، والدراسة، أمكن الوصول إلى عدة الطرق تعلمها في وقت قصير وبوجه معقول

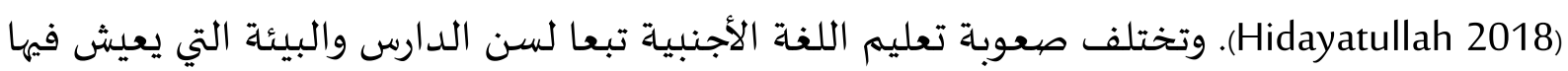
أثناء تعلماء اللغة العربياة، وتختلف أيضا صعوبة تعليم اللغة الأجنبية حيث طبيعتها، ومشابهاتها أو اختلافها في الصوت والكتابة للغة الدارس الأصلية(Al-Fauzan 2011; Albantani and Madkur 2018) . ولقد انتشرت اللغة العبية في أنحاء العالم انتشارا بقوة الإسلام والقرآن(Muhammad 2009) ، وإن الإسلام تأكرم الله الإنسان وشرفه بـه لكي يعيش أياما سعيدة في حياته على هذه الأرض، وإن ارتباط

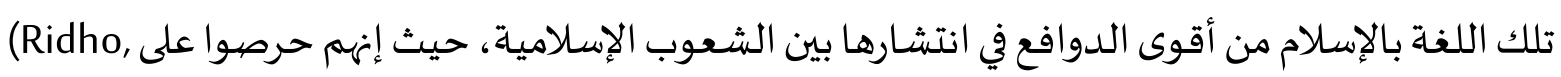
Mujahidin, and Al-Katani 2018).

ومن هنا يجب أخذ الطريقة السهلة لتعليم تلك اللغة. وعرف بأن اللغة العربيسة قد انتشر ودخل

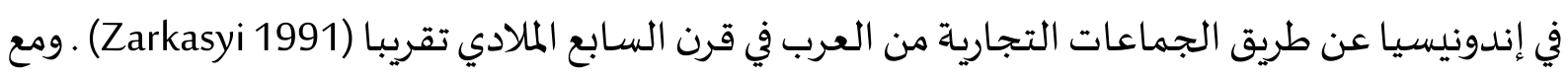
دخول اللغة العربية في إندونيسيا، حملت بعض الكلمات التي لا توجد من قبل عند إندونيسيين ثم أثر تأثيرا كبيرا على ثقافتهم، ولغتهم (Nasution 2019) . وقد تتجلى في اللغـة السندوية ظاهرة استخدام الكلمات 
والمصطلحات السندوية المقترضة من اللغة العربية في الحياة اليومية وإن جهل بعض السندويين أن هذه الكلمات والمصطلحات أخدت من اللغة العربية. لو عرفوا السندويين أن وجه الشبه بين اللغة العربية واللغة السندوية فجمعت هذه الكلمات تسهيلا تعلم اللغة العربية مع بيان بعض تغيرات في النطق والمعنى.

يعتمد الباحث في هذا البحث على المنهج المكتبي والوصفي، المنهج المكتبي هو المنهج الذي يعتمد على المكتبة والمراجع من الكتب والبحوث والمقالات. وهو يجري مكتبيا معتمد على البيانات والمعلومات

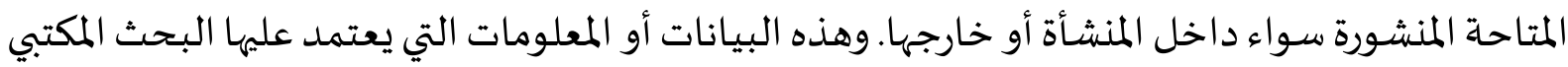

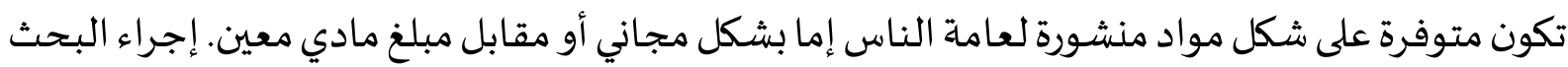

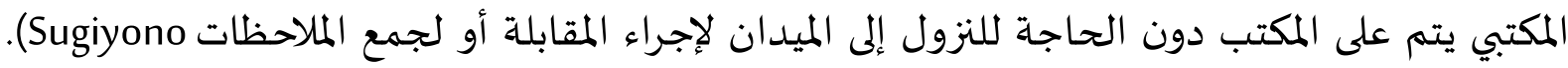



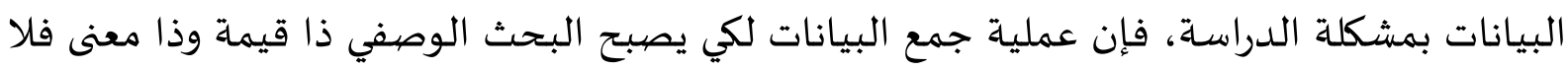

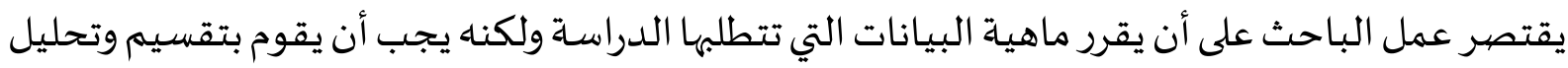

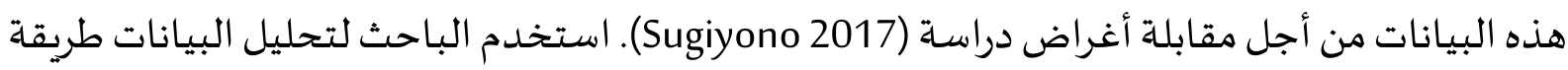

$$
\text { ماليس وهوبرمان ، وهي بثلاث الطرق جمع وحد البيانات، عرض البيان البيانات والاستنتاج. }
$$

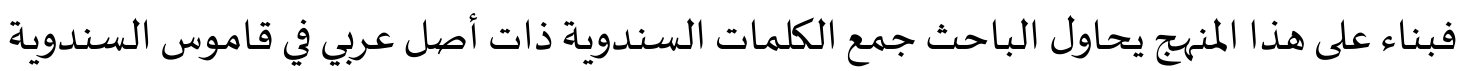

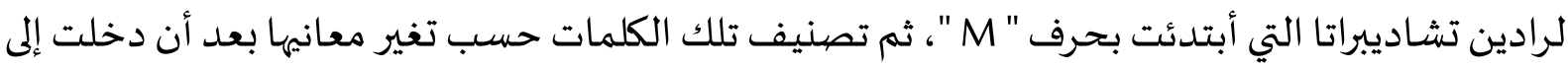
اللغة السندوية ويتبعها تحليل كل كلمة من الناحية النطقية والدلالية، وبعد ذلك قام الباحث بالائلاستفاديادة من تلك الكلمات في تعليم اللغة العربية لسندوين المبتدئين.

\section{المناقشة}

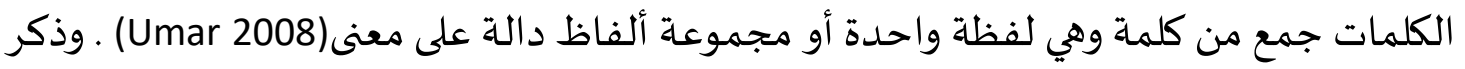



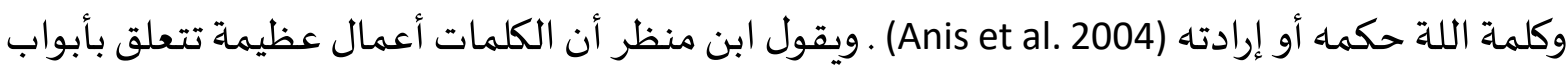


وملائمة لها ومنافع لا يخصيها من يصفيها (Kholil 1998) .

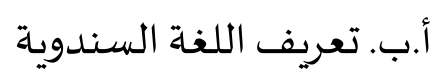

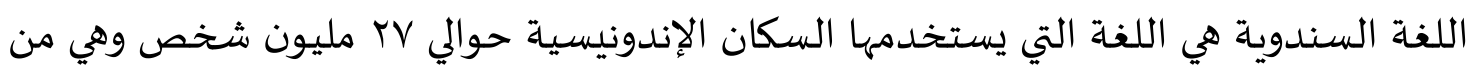

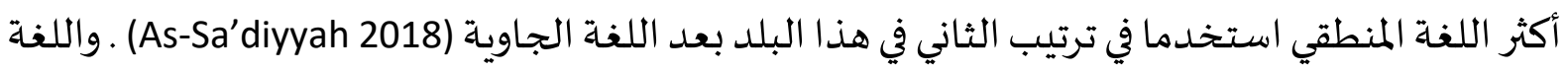

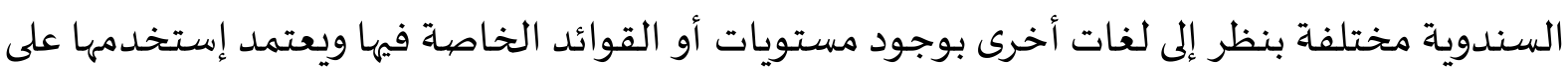


الغرض الذي نتحدث إليه أو بحسب مخاطبها أي مستوياتها وهي اللغة الطفولياة، واللغة اللطيفة، واللغة الشديدة (Sari and Yuliana 2015) . ومن هذا نعريف أن اللغة السندوية مختلفة عن لغات أخرى.

$$
\text { أ.ت. تعريف ذات أصيل عربي }
$$

ذات أصل هي التي بمعنى الإقتراض اللغوي، فهو عملية أخذ كلمة من لسـان إلى لسان أخر أي إدخال

Page | عنصر من لغة أجنبية إلى لغة ما، وهو ظاهرة لغوية عالمية لا تكاد تسلم منها لغة من اللغات، حيث تتابدل 155

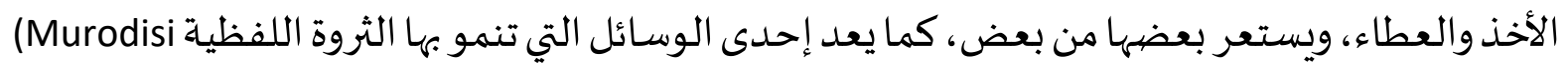
(2009. ويقول الأخر أنه إدخال عناصر من لغة أخرى سواء أكانت تلك العناصر كلمات أو أصهوات أو صيغا (Ba'labaky 1990) . وعربي هو نسبة إلى العرب. لمححة موجزة عن قاموس اللغة السندوية إن من تاريخ ليكسيكوغرافي ( Leksikografi ) السندويـة نعرف قاموس اللغة الذي ألفه رادين ستشايبراتا(Raden Satdjadibrata) ولد في سومادانخ اب أغوسطوس 1117 إم هو من ضمن القوامس

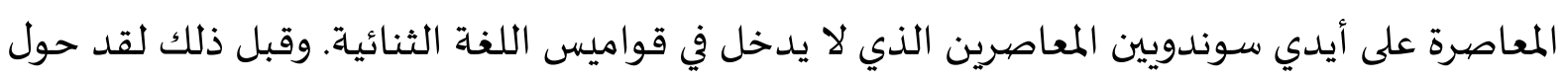
رادين آريا كوسومانينجات( Raden Arya Kusumaningrat) بتدوين قاموس ثنائي اللغة الملايوية - ميناية السندوية في عام لمOام، ولكن حتى الأن له يتم نشره. وقاموس السندوية - الإندونيسية الذي ألفه

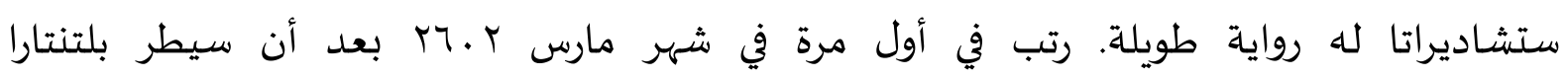

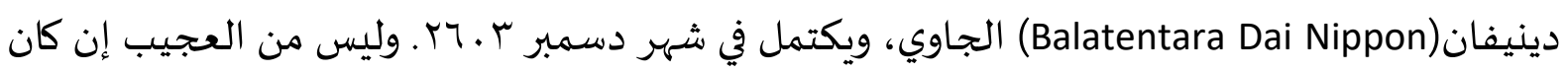

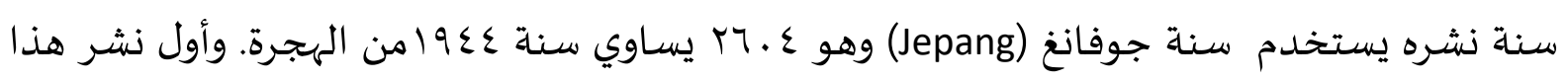
قاموس اللغة الثنائية في قاموس في عام عـ19 ، والثاني (الطبعة الثانية ) في عام ـ 190 ـ وبعد واحد وستين

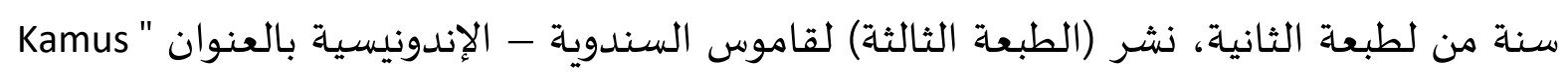
Sunda - Indonesia إن قاموس اللغة السندوية دون لسببين أسـاسين هما، الأول: محافظة للغة السندوية حيث إنها تراث غنى لا بد من رعايتها حتى تزال هذه اللغة باقية وتتطور بتقدم الزمان. والثاني: تسهيلا لمن يريد أن إن إندين يدرس اللغة السندوية حيث إنها يحتاج إلى مساعدة في فهم تلك اللغة (Satdjadibrata 2011). قبل أن دون قاموس اللغة السندوية فإن الغرب أخذوا اهتماما في تأليف قاموس اللغة السوندوية حيث إنهم اشتركوا في مسابقة تأليف قاموس سوندا تكميلا لقاموس دي ويلدي (Kamus de wilde)

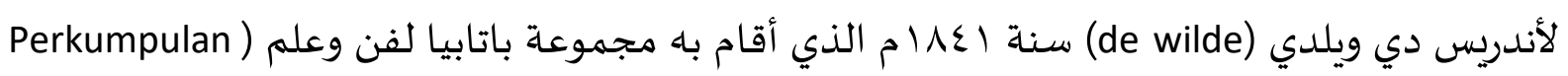

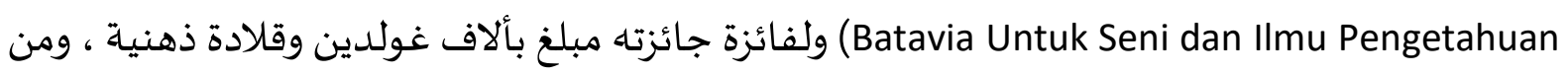

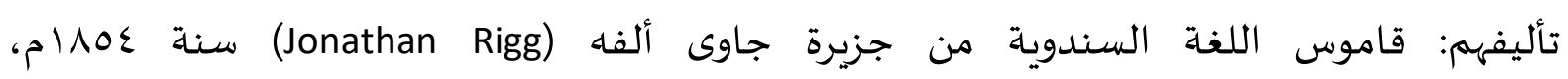
وقاموس Gouvernement Van Soendasch-Nederduitsch Woordenboek, op last van het

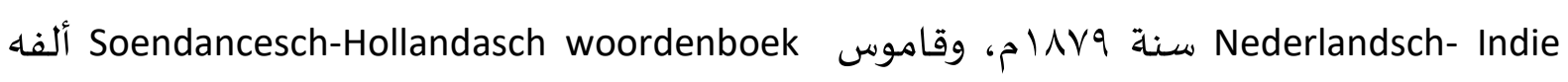
سنة ع (KN.Coohsma) 
وتطور قواميس السندوية التي تم طباعتها، هي منها: قاموس سندي- إندونيسي ألفه مامان سومنتري

وزميلة سنة ع ا9 ام، قاموس سوندى- سوندى وهو مجالدان ألفه أويون سوفيان أومساربو زميلة سنـة

مrurnia 2008)199 (K)

Page | 156

\begin{tabular}{|c|c|c|c|}
\hline أصلها عربي & الكلمات السـندوية & أصلها عربي & الكلمات السندوية \\
\hline مقلى & Mokla & معلوم & Ma'lum \\
\hline مؤمن & Mumin & مأموم & Mamum \\
\hline مؤكد & Muakad & معرفة & Maripat \\
\hline مؤلف & Mualap & معفو & Map \\
\hline معلم & Mualim & مذهب & Madhab \\
\hline مبذر & Mubadir & مغرب & Magrib \\
\hline  & Mud & مغربي & Magibi \\
\hline 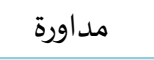 & Mudawarah & ماهر & Mahir \\
\hline مهاجر & Muhajir & مخلوق & Mahluk \\
\hline محرّم & Muharam & 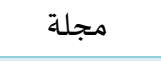 & Majalah \\
\hline مخلص & Muhlis & مجلس & Majlis \\
\hline محرم & Muhrim & مجموع & Majmu \\
\hline مقتصر & Muhtasor & مجوسي & Majusi \\
\hline معجزة & Mujijat & مقام & Makam \\
\hline مكلف & Mukalap & مقبول & Makbul \\
\hline مكنى & Mukena & معنى & Makna \\
\hline مقيم & Mukim & مكروه & Makruh \\
\hline مولود & Mulud & ملائكة & Malaikat \\
\hline مناجاة & Munajat & ملائكة & Malakat Maot \\
\hline منافق & Munapek & مضيارات & Malarat \\
\hline مناسبة & Munasabah & ملك & Malik \\
\hline 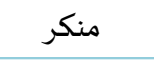 & Munkar & معلم & Malim \\
\hline موافق & Mupakat & منفعة من & Mangpaat \\
\hline مراد & Murad & مني & Mani \\
\hline مريد & Murid & موت & Maot \\
\hline مرشد & Mursid & مفهوم & Maphum \\
\hline مصيانف & Musanip & مرحوم & Marhum \\
\hline مسافر & Musapir & مرجان & Marjan \\
\hline مشاورة & Musawarah & مرتبة & Martabat \\
\hline مصيبة & Musibat & مسكت & Masakat \\
\hline موسيم & Musim & مسألة & Masalah \\
\hline مشكل & Muskil & مسبوق & Masbok \\
\hline مصلحة & Muslihat & مشهور & Mashur \\
\hline مسلم & Muslim & معصية & Masiat \\
\hline
\end{tabular}


Learning Arabic

\begin{tabular}{|c|c|c|c|}
\hline مسلمةة & Muslimat & مستجد & Masjid \\
\hline مشرك & Musrik & مشرق & Masrik \\
\hline مستحيل & Mustahil & مسطرة & Mastar \\
\hline مستجب & Mustajab & موجود & Maujud \\
\hline مستقيم & Mustakim & معونة & Maunat \\
\hline مستعمل & Mustamal & ميت & Mayit \\
\hline مصطفى & Mustapa & ملك & Milik \\
\hline مشتري & Mustari & منبر & Mimbar \\
\hline مطالعة & Mutalaah & معراج & Mired \\
\hline مطلق & Mutlak & مثل مثل & Misil \\
\hline مطمئنة & Mutmainah & مسكين & Miskin \\
\hline موجود & Mojud & مستحيل & Mohal \\
\hline
\end{tabular}

\section{أقسام تغيرات الكلمات ذات أصل عربي في القاموس.}

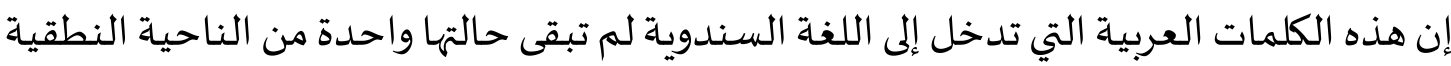
والدلالية، وانما طرأت فيها التغيرات، ومن حيث الدلالة يمكننا أن نقسم التغيرات إلى أربعاة يظهر تفصيلها

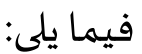

\begin{tabular}{|c|c|c|c|c|c|c|c|c|c|}
\hline \multicolumn{2}{|c|}{ انتقلت معانها } & \multicolumn{2}{|c|}{ ضـاقت معانيها } & \multicolumn{2}{|c|}{ اتسعت معانيها } & \multicolumn{4}{|c|}{ بقيت معانيها } \\
\hline ذات أصل & السكلدمات السية & ذات أصل & السكلمات السندية & ذات أصل & السـلدمات السية & ذات أصل & السندمات السية & ذات أصل العربي & السندلدوية الكلمات \\
\hline مجموع & Majmu & مناسبة & Munasabah & مذهب & Madhab & مجلة & Majalah & ماهر & Mahir \\
\hline مقام & Makam & مريد & Murid & مالك & Malik & مكروه & Makruh & مخلوق & Mahluk \\
\hline معلم & Malim & مغربي & Magribi & مضيارة & Malarat & منفعة & Mangpaat & مجلس & Majlis \\
\hline مسكت & Masakat & مقبول & Makbul & مني & Mani & مفهم & Maphum & ملائكة & $\begin{array}{c}\text { Malaikat } \\
\text { maot }\end{array}$ \\
\hline  & Mokla & معنى & Makna & مسلم & Muslim & مرتبة & Martabat & ملائكة & Malaikat \\
\hline مؤلف & Mualip & موت & Maot & معونة & Maunat & موجود & Maujud & معلوم & Ma'lum \\
\hline مداورة & Mudawarah & موافق & Mupakat & مولود & Mulud & معراج & Mired & مأموم & Ma'mum \\
\hline مكنى & mukena & مرجان & Marjan & مسالة & Masalah & مسطرة & Mistar & مرحوم & Marhum \\
\hline مناجاة & Munajat & 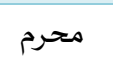 & Muharam & - & - & موجود & Mojud & مشهور & Mashur \\
\hline مصلحة & Muslihat & مسبوق & Masbuk & - & - & مؤلف & Mualip & معصية & Masiat \\
\hline فصان & Musonip & موسيم & Musim & - & - & مقيم & Mukim & مسجد & Masjid \\
\hline مشتري & Mustari & منبر & Mimbar & - & - & 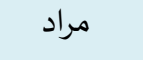 & Murad & ميت & Mayit \\
\hline
\end{tabular}


Learning Arabic

Page | 1 so

\begin{tabular}{|c|c|c|c|c|c|c|}
\hline Miskin & - & - & مغرب & Magrib & ملك & Milik \\
\hline - & - & - & مسافر & Musapir & مثل مثل & Misil \\
\hline- & - & - & مشاورة & $\begin{array}{c}\text { Musawa- } \\
\text { rah }\end{array}$ & مؤكد & Muakad \\
\hline - & - & - & مصيبة & Musibah & مبذر & Mubadir \\
\hline- & - & - & مشكل & Muskil & مد & Mud \\
\hline- & - & - & مسلمة & Muslimah & مهاجر & Muhajir \\
\hline- & - & - & مشرك & Musrik & مخلص & Muhlis \\
\hline- & - & - & مستجب & Mustajab & محرم & Muhrim \\
\hline- & - & - & مستعمل & musta'mal & مقتصر & $\begin{array}{c}\text { Muhtaso } \\
\mathrm{r}\end{array}$ \\
\hline- & - & - & مصطفى & Mustopa & معجزة & Mujijat \\
\hline - & - & - & مطالعة & Mutalaah & مكلف & Mukalap \\
\hline- & - & - & مطلق & Mutlak & منافق & Munapik \\
\hline- & - & - & مطمئن & Mutmain & منكر & Munkar \\
\hline- & - & - & معرفة & ma'ripat & مستحيل & Mustahil \\
\hline- & - & - & مستقيم & Mustakim & مؤمن & mu'min \\
\hline- & - & - & مشرك & Masrik & معفو & Maap \\
\hline
\end{tabular}

الجسلول r : أقسام تغيرات الكلمات ذات أصل عربي في القاموس

\section{نموذج تحليل الكلمات السندوية ذات أصل عربي والاستفاذة منها}

كلمة (munapik) وأصلها العربي (منافق)، تغير هذه الكلمة بحذف المد أي الألف الممدودة مع

تسكين الحرف الأخير. وفي اللغة العربية كلمة منافق هي اسم فاعل من نافق ومعناها هو أظهر خلاف ما

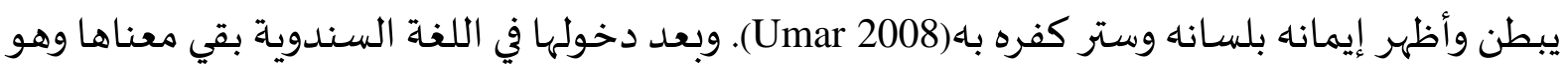
منافق كما عرفه العرب (Satdjadibrata 2011).

كلمة (musapir) وأصلها العربي (مسافر)، تغير هذه الكلمة بحذف المد أي الألف الممدودة مع تسكين الحرف الأخير. وكلمة مسافر في اللغة العبية هي اسم فاعل من سافر، ومعناها متعدد بحسب صيغها، الأول: سافر الشخص / سافر شخص إلى أبيه أي مض وارتحل، والثاني: سافرت عنها الحمى أي

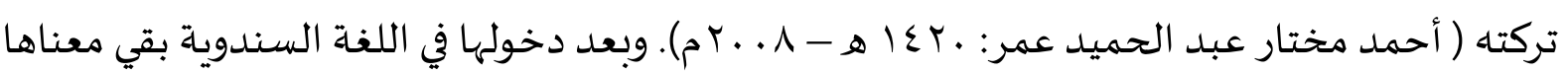




\section{ميكال : يا أستاذ أنا مسافر، وأصببت بالمصيبة.

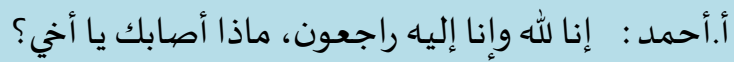

ميكال : إني مجوسي، وساحر ماهر مشهور مطلق على مرتبة الأعلى والمجتمع يعريفني أنني مسلما.

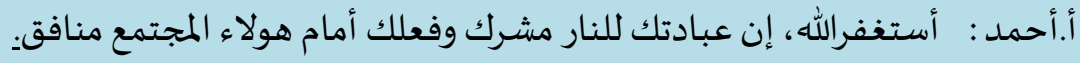
الرسم التوضيحي ا : نماذج تعليم الكلمات العببية بقيت معانها في اللغة السندوية في الحوار.

ستجد الطلاب في هذا الحوار كلمات معروفة لدي السندويين وهي : مسافر، ومصيباة، ومجوسي، وماهر، ومشهور، ومطلق، ومرتبة، ومشرك، ومنافق. ولا يحتاج المعلم إلى شرح هذه المفردات لتوافق المعاني في اللغة العربية واللغة السندوياة، ولم يبق المعلم إلا أن يبين مسألة اقتران المفردات بالضمائر مثل في كلمة " يعرفني" أو اقترن بالألف واللام مثل في " المصيبة".

الخلاصة

بناء على ما قد سبق من البحث وتحليل الكلمات السندوية ذات أصل عربي من حرف M في قاموس اللغة السندوية لرادين ستشـاديبرتا والقيام بالاستفادة منها في تعليم اللغة العربية للسندويين المبتدئين، توصلت الباحث إلى نتيجة، أن الكلمات السندوية التي لها أصالة عربية في قاموس اللغة السندوية لرادين ستشاديبرتاموجودة وهي كثيرة جدا، ولقد كشف وجودها وبلغت على إثنين وتسعين كلماة، وتلك الكلمات يقتصر أخذها من حرف M دون غيرها، وتم تحليلها ولم تبق حالتها واحدة من الناحية النطقية والدلالية، وإنما طرأت فهها التغيرات. ومن حيث الدلالة يمكننا أن نقسم التغيرات إلى أربعة أقسام: كلمات عربية بقيت معانيها في اللغة السندوية، كلمات عربية اتسعت معانيها في اللغة السندوياة، كلمات عربية ضاقت معانيها في اللغة السندويةة، كلمت عربية انتقلت معانيها إلى معان أخرى في اللغة السندوياة.

الالاستفادة

إن الاستفادة من الكلمات السندوية ذات أصل عربي في تعليم اللغة العربية للسندويين المبتدئين هي الطريقة الجيدة في مساعدة المعلمين في تطوير تديريسهم، بحيث لها دور في فهم معاني الكلمات والجمل العربية، وسهولة تعلم اللغة العربية في وقت قصير وفترة يسيرة، وذلك بإدخال تلك الكلمات في الحوارات، والنصوص، وإعراض معاني الكلمات، ووضعها في الجمل والتدريبات.

\section{المراجع}

Al-Adawiyyah, Rabiah. 2010. 'Tahlil Al-Akhto Fi Istikhdam Al-Domair Fi Al-Insya Al-Muwajjah Lada Talamidz Al-Shof Al-Tsani Min Madrasah Al-Wathaniyyah 16 Al-Mutawasithoh AlIslamiyyah Jakarta Al-Syarqiyyah'. Universitas Islam Negeri Syarif Hidayatullah Jakarta. Albantani, Azkia Muharom, and Ahmad Madkur. 2018. 'Think Globally, Act Locally: The Strategy of Incorporating Local Wisdom in Foreign Language Teaching in Indonesia'. In 
International Journal of Applied Linguistics \& English Literature, 1-8. Australia. http://dx.doi.org/10.7575/aiac.ijalel.v.7n.2p.1.

Al-Fauzan, Abdurrahman bin Ibrahim. 2011. Idoa't Limuallimi Al-Lugoh Al-Arabiyyah Ligoiri AnNatiqina Biha. Riyadh: Al-Arabiyyah Lil Jami'.

Alma'tuq, Ahmad Muhammad. 1996. Alhashilah Al-Lughowiyah Mashodiriha Wa Tanmiyatiha. Kuwait.

Anis, Ibrahim, Abdul Halim Muntashir, Athiah Al-Showalihi, and Muhammad Holfullah Ahmad. 2004. Al-Mu'jam Al-Wasith. Maktabah Al-Syuruq al-Dauliyyah.

As-Sa'diyyah, Halimah. 2018. 'Al-Kalimat Dzatu Asli Arabiy Fhi Qomus Al-Lugoh AsSundawiyyah Li Raden Sadjadibrata Min Harf A-J’. Sekolah Tinggi Ulmu Bahasa Arab Arraayah.

Ba'labaky, Ramzi Munir. 1990. Mu'jam Al-Mustalahat Al-Lugowiyyah Inggris-Arab. Beirut: Dar Al-IImi.

Firdaus, Rizal, Kurnia Afandi Al Farisi, and Robi Mandala. 2019. 'Istratijiyat Ta'lim Al-Lughoh AlArabiyyah Fi Ashri Aulamah'. Studi Arab 10 (2): 131-50. https://doi.org/10.35891/sa.v10i2.1857.

Hidayatullah, Achmad Diny. 2018. 'Al-Idārah al-Istirātijiyyah Fī Ta'līm al-Mahārāt alLughawiyyah'. Alsuna: Journal of Arabic and English Language 1 (2): 103-13. https://doi.org/10.31538/alsuna.v1i2.77.

Kholil, Hilmi. 1998. Al-Kalimah Daros Lughowiyyah Mu'jamiyyah. Alexandria: Dar Al-Ma;rifah Al-Jamiiyyah.

Kurnia, Atep. 2008. 'Perkembangan Kamus Sunda'. 2008. https://sundaislam.wordpress.com/2008/04/03/perkembangan-kamus-sunda/. 
Muhammad, Umar Hasba Rasul Usman. 2009. 'Ahamiyyah Lughah Al-Qur'an al-Karim Wa Intisyaruha Fi Malaysia'. Dirasat Da'wiyyah.

Murodisi, Jodi. 2009. 'Al-Aliyat Taulid Al-Mustolah Al-Lughoi'. Majallah Al-Dzakirah, 285-300.

Nasution, Nurmia. 2019. 'Al-Kalimat Al-Melayuwiyyah Dzatu Asli Arabiy Fhi Qomus Daya Walistifadah Minha Fhi Ta'lim Al-Lugoh Al-Arabiyyah Al-Melayuwiyyin Al-Mubtadiin Harf “I” Namudazan'. Sekolah Tinggi Ilmu Bahasa Arab Ar-Raayah Sukabumi.

Ridho, Fahmi, Endin Mujahidin, and Abdul Hayyi Al-Katani. 2018. 'Tariqah Ta'lim Al-Lughah Al'arabiyyah 'ala Manhaj Silsilah Al-'Arabiyyah Fi Jami'Ah Ar-Rayah Sukabumi'. In International Conference On Islamic Studies. Sukabumi.

Sari, Devita Nela, and Risti Yuliana. 2015. 'Kebudayaan Suku Sunda'. Surakarta.

Satdjadibrata, R. 2011. Kamus Sunda - Indonesia. Bandung: Kiblat Buku Utama.

Setyawan, Cahya Edi, and Muhamad Fathoni. 2019. 'Al-Manhaj al-Ilmiy Fī Ta'līm al-Lughah al'Arabiyah Fī al-Madrasah al-Thānawiyah al-Mu'allimīn al-Muḥammadiyyah Bi Yogyakarta'. Alsuna: Journal of Arabic and English Language 2 (2): 150-63. https://doi.org/10.31538/alsuna.v2i2.391.

Sugiyono. 2017. Metodologi Penelitian Pendidikan, Pendekatan Kuantitatif, Kualitatif Dan Riset Dan Pengembangan. Bandung: Alfabeta.

Umar, Ahmad Muhtar. 2008. Mu'jam Al-Lughoh Al-Mua'siroh. Cairo: A'lam Al-Kutub.

Zarkasyi, Ahmad Hidayatullah. 1991. 'Al-Lughah Al-Arabiyyah Fi Indonisia Dirasah Wa Tarikhiyyah'. Jamiah Al-Punjab. 